\title{
Effects of octreotide on circulating islet B cell products in endogenous hyperinsulinism
}

\author{
Andrew J. Krentz ${ }^{1}$, Jackie Pace ${ }^{2}$, Wendy Somerville ${ }^{2}$, Penelope M.S. Clark ${ }^{3}$ \\ and Malcolm Nattrass ${ }^{1}$
}

\author{
${ }^{1}$ The Diabetic Clinic, The General Hospital, Birmingham, ${ }^{2}$ Department of Care of the Elderly, Watford \\ General Hospital, and the ${ }^{3}$ Department of Clinical Biochemistry, Addenbrooke's Hospital, Cambridge, UK
}

\begin{abstract}
Summary: The role of somatostatin analogues in the medical management of insulinomas is unclear. We describe an elderly patient with clinical and biochemical features of endogenous hyperinsulinism attributable to a benign islet $B$ cell disorder whose incapacitating neuroglycopaenic symptoms responded dramatically to octreotide $50 \mu \mathrm{g}$ subcutaneously at $2200 \mathrm{~h}$ each night. Octreotide suppressed inappropriate plasma concentrations of insulin thereby preventing fasting hypoglycaemia. Fasting concentrations of proinsulin, and 32-33 split proinsulin, as determined by two-site monoclonal antibody-based immunoradiometric assays, were also suppressed by octreotide.
\end{abstract}

\section{Introduction}

Surgical excision remains the definitive treatment for benign functioning insulinomas ${ }^{1,2}$ with longterm medical treatment usually being reserved for patients who refuse surgery or those in whom surgery is deemed inappropriate. ${ }^{3}$ However, the therapeutic options for medical management of endogenous hyperinsulinism remain relatively limited. The anti-hypertensive agent diazoxide has been used successfully to inhibit insulin secretion by insulin-secreting tumours but is commonly associated with significant adverse effects including fluid retention and hirsutism. ${ }^{4}$ The efficacy of alternative drugs such as verapamil and betablockers remains unclear. ${ }^{4}$

Octreotide is a long-acting analogue of somatostatin with potent suppressive effects on a number of endogenous hormones including insulin. ${ }^{5,6} \mathrm{How}-$ ever, the role of octreotide in the management of benign insulinomas remains to be clarified. The literature contains conflicting reports of efficacy ${ }^{7}$ contrasting with worsening of fasting hypoglycaemia. $^{4,8-10}$ We describe an elderly man with clinical and biochemical features of an insulinsecreting tumour whose symptoms were abolished by a single nightly dose of octreotide. Octreotide suppressed fasting concentrations of circulating insulin and islet B cell conversion intermediates thereby preventing hypoglycaemia.

Correspondence: Andrew J. Krentz, M.D., M.R.C.P., The General Hospital, Steelhouse Lane, Birmingham B4 $6 \mathrm{NH}$, UK.

Accepted: 12 February 1993

\section{Methods}

Plasma immunoreactive insulin, ${ }^{11}$ proinsulin, and C-peptide concentrations were determined using double antibody radioimmunoassays (RIAs). Plasma concentrations of insulin, proinsulin, and 32-33 split proinsulin were determined using highly specific two-site monoclonal antibodybased immunoradiometric assays (IRMAs) with between assay coefficients of variation (CVs) of $15 \%$ or less and detection limits ranging from 0.8 to $2.5 \mathrm{pmol} / 1$. $^{12}$ Venous plasma glucose concentrations were determined using glucose oxidase methods on fluoride-oxalate samples.

\section{Patient}

An 80 year old man presented with a 2 week history of episodic confusion and agitation occurring each morning before breakfast. Two weeks earlier he had undergone a transurethral prostatectomy for benign disease which was complicated by an acute postoperative Gram-negative septicaemia. Past medical history included asymptomatic chronic atrial fibrillation treated with digoxin. There was no other relevant drug history nor any history of alcohol consumption.

Physical examination revealed an afebrile patient with a body mass index of $24 \mathrm{~kg} / \mathrm{m}^{2}$ and an irregular pulse. Atrial fibrillation was confirmed by electrocardiography; chest and abdominal radiology were unremarkable. Blood leucocyte count was normal. Computerized tomography (CT) revealed no significant intracranial abnor- 
mality although electro-encephalography revealed an abnormal record suggestive of a generalized metabolic disorder. Early one morning shortly after admission the patient was discovered unrousable in bed. Capillary blood glucose concentration measured at the bedside using a reflectance meter was $2.0 \mathrm{mmol} / \mathrm{l}$. The administration of glucagon $1 \mathrm{mg}$ subcutaneously was followed by a rapid improvement in level of consciousness. This pattern of events was repeated on subsequent mornings with fasting venous blood glucose concentrations of $1.9 \mathrm{mmol} / 1$ and $1.8 \mathrm{mmol} / 1$ in concert with plasma immunoreactive insulin concentration (RIA) of $102 \mathrm{pmol} / 1$ and $45 \mathrm{pmol} / 1$ (normal $<15 \mathrm{pmol} / \mathrm{l}$ ), respectively. Fasting plasma C-peptide concentration was inappropriately normal at $528 \mathrm{pmol} / 1$ during hypoglycaemia with an elevated plasma proinsulin concentration (RIA) of $30 \mathrm{pmol} / 1$ (normal $<10$ ). Alternative causes of fasting hypoglycaemia were excluded as far as possible: renal and hepatic function were normal on routine biochemical screening, and plasma cortisol response to $250 \mu \mathrm{g}$ Synacthen was normal. There were no suspicious features to suggest surreptitious sulphonylurea consumption. The temporal relationship between the onset of hypoglycaemic symptoms and the antecedent septicaemic illness appeared to be consistent with reduced caloric intake resulting in hitherto borderline fasting hypoglycaemia becoming clinically overt.

Ultrasound and CT scanning with contrast enhancement, while providing good visualization of the pancreas, failed to localize a tumour. Thus the differential diagnosis lay between a small single insulinoma, diffuse adenomatosis, or adult nesidioblastosis. ${ }^{4}$ Medical therapy was therefore initiated with the objective of avoiding invasive investigations and the prospect of distal pancreatectomy if a tumour could not be identified at laparotomy. Diazoxide was considered to be relatively contraindicated by the presence of chronic cardiovascular disease. A trial of octreotide $50 \mu \mathrm{g}$ subcutaneously at $2200 \mathrm{~h}$ was com- menced after full explanation of the experimental $\stackrel{2}{3}$ nature of the treatment and possible adverse $\stackrel{\mathbb{Q}}{\stackrel{1}{2}}$ effects. The use of octreotide was approved by the $C$. Research Ethics Committee of South Birmingham $\vec{\Rightarrow}$ Health Authority. The therapeutic effect of oct- $\stackrel{?}{+}$ reotide was dramatic with prompt resolution of all $\bar{C}$ neuroglycopaenic symptoms. Octreotide effect- $\frac{\bar{\sigma}}{\bar{D}}$ ively suppressed inappropriately elevated fasting $\frac{\rho}{\sigma}$ concentrations of insulin, proinsulin, and 32-33 split proinsulin thereby eliminating early morning $\%$ hypoglycaemia (Table I). During the week follow- $\overrightarrow{0}$ ing the introduction of octreotide fasting plasma glucose concentrations ranged between 4.0 and $\vec{\omega}$ $7.0 \mathrm{mmol} / 1$. To date, the patient has remained $\frac{\rho}{8}$ symptom-free on a single self-administered nightly $\frac{0}{7}$ dose during 12 months of follow-up with fasting blood glucose concentrations of $4.5-5.0 \mathrm{mmol} / 1$. के Octreotide has been well tolerated and no side- $\stackrel{\infty}{=}$ effects of therapy have been encountered.

\section{Discussion}

The biochemical diagnosis of insulinomas relies on the demonstration of inappropriate normal or $\frac{\vec{D}}{\mathbb{D}}$ elevated circulating insulin concentrations in the 3 presence of fasting hypoglycaemia. Care should be $\underset{\text { }}{ }$ taken to exclude the possibility of drug-induce $\overrightarrow{\vec{\theta}}$ hyperinsulinaemia, especially surreptitious med $\&$ cation with sulphonylureas. ${ }^{1}$ The management ${ }^{\circ}$ benign insulinomas comprises surgical excision wherever possible; long-term medical therapy is usually reserved for selected cases such as the patient reported here.

Somatostatin analogues have been successfully $\stackrel{\mathbb{Q}}{\stackrel{2}{\circ}}$ employed in the management of hyperinsulinaemia $\overrightarrow{\vec{O}}$ in infancy ${ }^{13}$ and in insulin-secreting tumours in 3 adults. ${ }^{7}$ However, beneficial effects of octreotide have not been universally reported. ${ }^{4}$ Some patients with markely elevated plasma immunoreactive $\bar{O}$ insulin concentrations have shown no improve- 3 . ment. ${ }^{14,15}$ Suppression of counter-regulatory hormone secretion has been implicated in reports of exacerbation of hypoglycaemia during treatment

Table I Fasting venous plasma concentrations of glucose, insulin, and islet B cell conversion intermediates prior to, and on day 5 and day 6 following the initiation of octreotide $50 \mu \mathrm{g}$ subcutaneously at $2200 \mathrm{~h}$ each night

\begin{tabular}{|c|c|c|c|c|c|}
\hline & $\begin{array}{l}\text { Glucose } \\
(\mathrm{mmol} / \mathrm{l})\end{array}$ & $\begin{array}{c}\text { Insulin } \\
\text { (pmol/l) }\end{array}$ & $\begin{array}{c}\text { Proinsulin } \\
(\mathrm{pmol} / \mathrm{l})\end{array}$ & $\begin{array}{c}\text { 32-33 split pro- } \\
\text { insulin } \\
(\mathrm{pmol} / \mathrm{l})\end{array}$ & $\begin{array}{c}\text { Total } \\
(\text { pmol/l) }\end{array}$ \\
\hline \multicolumn{6}{|c|}{ Pre-octreotide } \\
\hline & 1.8 & 61 & 15.0 & 5.5 & 81.5 \\
\hline \multicolumn{6}{|c|}{ Post-octreotide $50 \mu \mathrm{g}$ at $2200 \mathrm{~h}$} \\
\hline Day 5 & 5.8 & 24 & 6.0 & $<1.0$ & 31.0 \\
\hline Day 6 & 5.3 & 21 & 5.4 & $<1.0$ & 27.4 \\
\hline
\end{tabular}


with octreotide. ${ }^{8}$ These caveats notwithstanding, several successful treatment regimens have been described including multiple daily subcutaneous injections $s^{4,9}$ and continuous subcutaneous infusion regimens. $^{7}$

Approximately $80 \%$ of insulinomas are reported to secrete an excess of proinsulin relative to immunoreactive insulin. ${ }^{16,17}$ However, the literature concerning immunoreactive insulin and proinsulin concentrations in insulin-secreting tumours is largely derived from radioimmunoassays characterized by significant crossreactivity between insulin and proinsulin-like molecules. ${ }^{18,19} \mathrm{We}$ therefore measured plasma insulin and islet $B$ cell conversion intermediates using two-site immunoradiometric assays. ${ }^{12}$ While the role of specific assays of proinsulin-like molecules in the diagnosis of insulinomas has yet to be clearly established several observations provide support for the diagnosis of insulinoma in our patient. First, fasting plasma insulin concentration was not suppressed in the presence of hypoglycaemia. ${ }^{20}$ Second, fasting proinsulin concentration was elevated during hypoglycaemia. ${ }^{21}$ Similarly, the molar ratio of (proinsulin $+32-33$ split proinsulin) to (insulin + proinsulin $+32-33$ split proinsulin) expressed as a percentage was elevated at $25.1 \%$ compared to $9.4 \% \pm 1.0$ (mean \pm s.e. in healthy middle aged subjects). ${ }^{22}$ Third, the fasting plasma insulin: glucose ratio was elevated at $34 \%$ (normal: $10.1 \pm 1.0 \%)^{22}$ a biochemical feature characteristic of states of endogenous hyperinsulinism. ${ }^{4}$

Octreotide had a marked effect on circulating concentrations of islet $B$ cell products with suppression of fasting concentrations of insulin, proin-

\section{References}

1. Harrison, T.S., Child, C.G., Fry, W.J., Floyd, J.C. Jr \& Fajans, S.S. Current surgical management of functioning islet tumours of the pancreas. Ann Surg 1973, 178: 485-495.

2. Stefanini, P., Carboni, M., Patrassi, N. \& Basoli, A. Beta-islet cell tumours of the pancreas: results of a study on 1,067 cases. Surgery 1974, 75: 597-609.

3. Marks, V. \& Rose, F.C. Hypoglycaemia, 2nd ed. Oxford, Blackwell Scientific Publications, Oxford, 1981.

4. Fajans, S.S. \& Vinik, A.I. Insulin-producing islet cell tumours. Endocrinol Metabol Clinics North Am 1989, 18: 45-74.

5. Rosenberg, J.M. Octreotide: a synthetic analog of somatostatin. Drug Intell Clin Pharmacy 1988, 22: 748-754.

6. Katz, M.D. \& Erstad, B.L. Octreotide, a new somatostatin analogue. Clin Pharmacol 1989, 8: 255-273.

7. Laron, Z. Somatostatin analogues in the management of beign insulinomas. Israeli J Med Sci 1990, 26: 1-2.

8. Stehouwer, C.D.A., Lems, W.F., Fischer, H.R.A., Hackeng, W.H.L. \& Naafs, M.A.B. Aggravation of hypoglycaemia in insulinoma patients by the long-acting somatostatin analogue octreotide (Sandostatin). Acta Endocrinol 1989, 121: $34-40$.

9. Maton, P.N. The use of long-acting somatostatin analogue, octreotide acetate, in patients with islet cell tumours. Gastroenterol Clinics North Am 1989, 18: 847-863. sulin, and 32-33 split proinsulin, the latter being suppressed below the detection limit of the assay. The ratio of total proinsulin-like molecules to insulin was not significantly altered by octreotide. Since proinsulin-like molecules are characterized by lower biological activities than insulin ${ }^{23}$ it seems likely that suppression of insulin concentrations were primarily responsible for the improvement observed in fasting plasma glucose concentrations. Whether the response of an insulinoma to octreotide is dependent on the relative secretion of insulin or proinsulin-like molecules or whether the response of solitary islet B cell tumours is comparable with that of multiple islet adenomatosis or adult nesidioblastosis ${ }^{4}$ has not been determined.

In summary, a single nightly dose of octreotide eliminated fasting hypoglycaemia in our patient through suppression of circulating insulin concentrations. Fasting concentrations of proinsulin and $32-33$ split proinsulin were also suppressed. The case reported indicates that octreotide can be an effective and well-tolerated long-term medical treatment for certain patients with endogenous hyperinsulinism.

\section{Acknowledgements}

We thank Dr Hiliary Skene-Smith for performing the ultrasound and CT studies. Immunoreactive insulin, proinsulin, and C-peptide concentrations were kindly measured by the Hammersmith Hospital, London and the University of Guildford, Surrey, UK. The technical assistance of the Clinical Chemistry Department of the General Hospital, Birmingham, is gratefully acknowledged.

10. Battershill, P.E. \& Clissold, S.P. Octreotide. Drugs 1989, 38: 658-702.

11. Hales, C.N. \& Randle, P.J. Immunoassay of insulin with insulin antibody precipitate. Biochem $J$ 1963, 88: 137-146.

12. Sobey, W.J., Beer, S.F., Carrington, C.A. et al. Sensitive and specific two-site immunoradiometric assays for human insulin, proinsulin, 65-66 split and 32-33 split proinsulin. Biochem J 1989, 260: 535-541.

13. Glaser, B., Landau, H., Smilovici, A. \& Nesher, R. Persistent hyperinsulinaemic hypoglycaemia of infancy; long term treatment with the somatostatin analogue Sandostatin. Clin Endocrinol 1989, 31: 71-80.

14. Boden, G., Ryan, I.G. \& Schuman, C.R. Ineffectiveness of SMS 201-995 in severe hyperinsulinaemia. Diabetes Care 1988, 11: 664-668.

15. Longnecker, S.M. Somatostatin and octreotide: literature review and description of therapeutic activity in pancreatic neoplasia. Drug Intell Clin Pharmacy 1988, 22: 99-106.

16. Sherman, B.M., Pek, S., Fajans, S.S. et al. Plasma proinsulin in patients with functioning pancreatic islet cell tumors. J Clin Endocrinol Metabol 1972, 35: 271-280.

17. Cohen, R.M., Given, B.D., Licinio-Paixao, J. et al. Proinsulin radioimmunoassay in the evaluation of insulinomas and familial hyperproinsulinaemia. Metabolism 1986, 35: 1137-1146. 
18. Gray, I.P., Siddle, K., Docherty, K., Frank, B.H. \& Hales, C.N. Proinsulin in human serum: problems in measurement and interpretation. Clin Endocrinol 1984, 21: 43-47.

19. Clark, P.M.S. \& Hales, C.N. Assay of insulin: In: Williams, G. \& Pickup, J. (eds) Textbook of Diabetes. Oxford, Blackwell Scientific, 1991, pp. 335-347.

20. Service, F.J. Hypoglycemia. Endocrinol Metabolism Clinics North Am 1988, 17: 601-616.

21. Hale, P.J., Djurup, R., Baddeley, R.M. \& Nattrass, M. Insulin and proinsulin concentrations in patients with insulinoma before and after surgical treatment. Diabetes Nutr Metab 1991, 4: 113-116.
22. Williams, D.D.R., Byrne, C., Clark, P.M.S. et al. Raised proinsulin concentration as early indicator of beta cell dysfunction. Br Med J 1991, 303: 95-96.

23. Peavy, D.F., Brunner, M.R., Duckworth, W.C., Hooker, C.S. \& Frank, B.H. Receptor binding and biological potency of several split forms (conversion intermediates) of human proinsulin. Studies in cultured IM-9 lymphocytes and in vivo and in vitro in rats. J Biol Chem 1985, 260: 13989-13994.

\title{
Cardiac arrest: a rare complication of pallid syncope?
}

\author{
Bola Taiwo and Alex H. Hamilton
}

General Infirmary at Leeds, Great George Street, Leeds, West Yorkshire LS1 3EX, UK

\begin{abstract}
Summary: Cardiac arrest is rare in children. Breath-holding, on the other hand, is fairly common. We report a case in which one complicated the other with serious consequences. A review of the literature on the subject was undertaken.
\end{abstract}

\section{Introduction}

Pallid syncope (reflex anoxic seizure) is a fairly common childhood event that is probably underrecognized. It has been reported that $4.6-46.2 \%$ of a childhood population suffer breath-holding attacks of some form and $1 \%$ have pallid syncope, the others having the more commonly diagnosed and better understood cyanotic variety. ${ }^{1}$ Pallid syncope is distinguished by the child's obvious pallor during the attack, together with other signs suggestive of vagal overactivity. In a small number of patients with very frequent attacks, treatment with atropine has been shown to be effective. ${ }^{2}$

The diagnosis can be further established by the demonstration of vagal asystole from eyeball compression, a procedure said to be safe and free of complications, the cardiac standstill being selflimiting. ${ }^{3}$

These events are often very dramatic and frightening to the parents, but fundamentally harmless; we report the case of a child with a previous history of attacks suggestive of pallid syncope, who suffered an unexplained cardiac arrest.

Correspondence: B. Taiwo, F.R.C.S., Department of Surgery, Hemel Hempstead General Hospital, Hillfield Road, Hemel Hempstead, Herts HP2 4AD, UK.

Accepted: 22 February 1993

\section{Case report}

A 21 month old child had been entirely well in the past. He had a history of frequent episodes of breath-holding, starting at the age of about $6 \%$ months, during which he is said to have become $\stackrel{\varnothing}{\circ}$ profoundly pale and his parents report having been $\overrightarrow{\overrightarrow{0}}$ deeply alarmed by these in the past, although no 3 hospital contact had resulted. The patient is the $\bar{T}$ only child of the couple, neither of whom has a family history of breath-holding or sudden infant death syndrome.

On the occasion of his admission, he is said to have been well. His parents reported that they had had an argument during the early evening and a training shoe was thrown; this accidentally struck

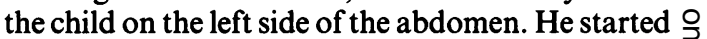
to cry, held his breath, arched his back and his eyes $\rightarrow$ rolled upwards. His father picked him up, only for him to become pale and limp.

One parent began mouth-to-mouth resuscitation of whilst the other called an ambulance. The $\tilde{N}$ paramedically trained crew arrived 4 minutes later $\underset{\omega}{N}$ and found him in asystole. He was intubated and ${ }^{2}$ cardiopulmonary resuscitation was commenced in 0 the ambulance en route to hospital; atropine and $\Phi$ adrenaline were given via the endotracheal tube $\stackrel{\odot}{+}$ without success. The accident and emergency 0 department was reached 25 minutes after the first call. 